\title{
BALANÇO ENERGÉTICO EM GALPÃO DE FRANGOS DE CORTE ${ }^{1}$
}

\section{TÂNIA M. B. SANTOS ${ }^{2}$, JORGE DE LUCAS JÚNIOR ${ }^{3}$}

RESUMO: Com o objetivo de avaliar o fluxo de energia em galpão de frangos de corte, realizou-se estudo de balanço energético após acompanhamento de oito lotes de criação, em galpão comercial da empresa Frango Sertanejo, Sertãozinho - SP. Foi quantificado o poder calorífico de cada componente envolvido no processo de produção (direto e indireto, entradas e saídas), utilizando-os posteriormente para o cálculo do coeficiente de eficiência energética. Determinaram-se os consumos de ração $(\mathrm{kg})$, produção de frango vivo $(\mathrm{kg})$, aves mortas/descartadas $(\mathrm{kg})$, produção de cama de frango $(\mathrm{kg})$, água $(\mathrm{L})$, gás liquefeito de petróleo - GLP $(\mathrm{kg})$, energia elétrica $(\mathrm{kWh})$, combustíveis $(\mathrm{L})$, mão-de-obra (hora-homem), máquinas e implementos (horas) e instalações e equipamentos ( $\mathrm{m}^{2}$ e horas). O fluxo líquido de energia demonstrou que a atividade possui alto consumo energético, apresentando eficiência energética de $28 \%$. Da energia direta de entrada, $10,2 \%$ corresponde à maravalha; $0,3 \%$ às aves; $86,5 \%$ à ração; $0,8 \%$ à eletricidade, e $2,1 \%$ ao GLP, e da energia de saída, $46,7 \%$ poderia retornar na forma de biogás, por meio da biodigestão anaeróbia da cama, gerando economia, já que se deixa de adquirir GLP para consumo no galpão.

PALAVRAS-CHAVE: biogás, eficiência energética, fluxo de energia.

\section{ENERGETIC BALANCE IN POULTRY HOUSE}

SUMMARY: This work aimed to evaluate the energy balance in broiler house. It was studied eight broiler flocks in a commercial broiler house in Sertanejo Poultry Industry (Sertãozinho - SP, Brazil). It was quantified the caloric power of each component that involves the production process (direct and indirect, in and out), that was used in the calculation of the energetic efficiency coefficient. The food consumption $(\mathrm{kg})$, broiler live weight $(\mathrm{kg})$, dead birds/refused $(\mathrm{kg})$, poultry litter production $(\mathrm{kg})$, water $(\mathrm{L})$, liquefied petroleum gas $(\mathrm{kg})$, electric energy $(\mathrm{kWh})$, fuel (L), machinery and implements (hours) and installation and equipments ( $\mathrm{m}^{2}$ and hours) were evaluated. The energy flow obtained by energetic balance showed that the activity presented high energy consumption, with $28 \%$ of energetic efficiency. From the direct energy input in the system, $10.2 \%$ concerned to the shaving wood, $0.3 \%$ to the birds, $86.5 \%$ to the diet, $0.8 \%$ to the electricity and $2.1 \%$ to the LPG. About the output energy, $46.7 \%$ could return to the system in the biogas form, generated from the anaerobic digestion of poultry litter.

KEYWORDS: biogas, energy flow, energetic efficiency.

\section{INTRODUÇÃO}

Toda atividade agropecuária se desenvolve em áreas que eram parte de um ecossistema natural. Com a chegada do homem e suas práticas agrícolas, essas áreas passaram a funcionar como agroecossistemas, que são uma fração do ecossistema que tem seus ciclos biogeoquímicos intencionalmente alterados pelo homem, com o objetivo de aumentar a produtividade de alguns

\footnotetext{
${ }^{1}$ Parte da Tese de Doutorado defendida pelo primeiro autor no Programa de Pós-Graduação em Produção Animal - FCAV-UNESP, Jaboticabal. Pesquisa Financiada pela Fundação de Amparo à Pesquisa do Estado de São Paulo - FAPESP.

2 Zootecnista, Prof. Adjunto, Universidade Estadual de Mato Grosso do Sul - UEMS - Unidade Universitária de Aquidauana, Rod. Aquidauana-Cera km 12, Aquidauana - MS, Fone: (0XX67) 241.4250, e-mail: santostm@ terra.com.br

${ }^{3}$ Eng. Agrônomo, Prof. Titular, Departamento de Engenharia Rural, FCAV/UNESP-Jaboticabal - SP.

Recebido pelo Conselho Editorial em: 18-2-2003

Aprovado pelo Conselho Editorial em: 8-12-2003
} 
organismos nativos ou possibilitar a produção de organismos exógenos. O agroecossistema e o ambiente circundante estão continuamente trocando matéria, energia, informação e vida, nas suas diversas formas; é o balanço dessas trocas que determina seus impactos, sejam ambientais, sejam econômicos (CAMPANHOLA et al., 1996).

Balanço energético é a apuração da energia investida num sistema de produção ou até mesmo de um país, como o Balanço Energético Nacional - BEN, instituído em 1976 e publicado anualmente pelo Ministério de Minas e Energia do Governo Brasileiro. É calculado por meio da análise do processo de produção e pela análise das matrizes de entrada e saída de energia, as quais são calculadas por meio do poder calorífico das matérias-primas envolvidas no processo (PIMENTEL, 1980 e BULLARD, 1976, citado por ULBANERE, 1988) e permite a identificação se o país ou setor de produção apresentou saldo energético favorável.

As entradas e saídas são condicionadas pelas complexas estruturas e funções internas do sistema. Se funcionar em desequilíbrio, um agroecossistema tende a perder a capacidade produtiva (CAMPANHOLA et al., 1996).

Os padrões de consumo de energia e, notadamente, a oferta de energia proveniente de diferentes fontes caracterizam o comportamento do balanço energético. Se comparados, o BEN da década de 70 no Brasil e o BEN de anos recentes, observa-se que a viabilidade energética do álcool interfere de forma positiva no balanço final.

Da mesma forma, pode acontecer nos sistemas de produção, visto que, de forma geral, a maioria dos sistemas de produção é consumidor ativo de energia elétrica. Como todo processo de produção produz resíduos e todo resíduo armazena alguma energia, os sistemas de produção podem reverter esse resíduo em energia, baratear seu custo de produção e funcionar de forma energeticamente equilibrada. Um exemplo característico é o setor sucroalcooleiro. As usinas de álcool e açúcar produzem energia a partir dos seus resíduos (bagaço de cana e vinhaça), utilizando-a de forma direta (queima, biogás) ou por intermédio de co-geração (energia elétrica a partir do bagaço de cana), tornando, dessa forma, seu fluxo energético mais favorável, ambiental e economicamente.

A avicultura é uma atividade com alto consumo energético, porém, também tem a característica de produzir resíduos com considerável potencial energético, como a cama de frango que, ao ser processada de forma a disponibilizar essa energia, poderia contribuir para um equilíbrio energético nas operações que se desenvolvem dentro do galpão.

O balanço energético tem estreita relação com o balanço econômico, e sua importância no setor agropecuário tem sido demonstrada em artigos, tais como a análise dos balanços energéticos e econômicos da produção de milho; refinação do óleo de amendoim; produção de silagem de milho, e em granjas de postura (ULBANERE, 1988; GABRIEL et al., 1993a,b; CAMPOS et al., 1998 e CARVALHO, 1999).

Segundo OSTRANDER (1980), a indústria avícola tem melhorado sua eficiência, tornando-se uma das mais eficientes conversoras de energia da dieta em proteína entre os sistemas de produção animal. Segundo esse autor, dentro do setor avícola, o maior consumidor de energia é o sistema de produção de perus, seguido pelo sistema de produção de ovos; entretanto, esse último possui melhor coeficiente energético. Sistemas de produção de frangos de corte são os menos eficientes na utilização de energia, considerando-se as entradas e saídas.

Com o objetivo de avaliar o fluxo de energia em galpão de frangos de corte, realizou-se um estudo de balanço energético, verificando-se as formas de energia direta e indiretamente envolvidas no seu processo de produção. 


\section{MATERIAL E MÉTODOS}

O estudo foi realizado com base em estimativas de entradas e saídas de energia, obtidas durante o acompanhamento de oito lotes de frangos de corte (janeiro-1998 a agosto-1999), em galpão comercial pertencente à Empresa Frango Sertanejo, localizada no município de Sertãozinho - SP.

Neste estudo, não foram incluídos insumos energéticos provenientes dos setores de suporte da produção de frangos de corte, como armazenagem, distribuição, sistema de crédito, fábrica de ração, matéria-prima para a fabricação da ração, bens de capital e outros, bem como os coeficientes energéticos de medicamentos, vacinas e produtos desinfetantes. Foi quantificado o poder calorífico de cada componente envolvido no processo de produção de frangos de corte (direto e indireto, entradas e saídas), utilizados posteriormente para cálculo do coeficiente de eficiência energética. Dessa forma, foram determinados os consumos de ração $(\mathrm{kg})$, produção de frango vivo (kg), aves mortas e descartadas $(\mathrm{kg})$, produção de cama de frango $(\mathrm{kg})$, água $(\mathrm{L})$, gás liquefeito de petróleo - GLP (kg), energia elétrica $(\mathrm{kWh})$, combustíveis (L), mão-de-obra (hora-homem), máquinas e implementos (horas) e instalações e equipamentos ( $\mathrm{m}^{2}$ e horas).

\section{Quantificação dos componentes energéticos direta e indiretamente envolvidos no sistema de produção de frangos de corte}

- Consumo de combustíveis: O óleo diesel (L) foi quantificado mediante abastecimentos das máquinas antes e após as operações no galpão, anotando-se também o número de horas gastas por essas máquinas. A quantidade de óleo lubrificante e graxa consumida (L) foi estimada com base na ficha de controle de manutenção individual das máquinas e implementos, correlacionados com o tempo de utilização de cada um.

- Consumo de água, GLP e energia elétrica: Em razão da dificuldade na colocação de registro individual na entrada do galpão estudado, o consumo de água (L) no galpão foi estimado a partir do consumo total de água na granja, dividindo-se o montante entre todos os galpões existentes e correlacionando-o com o número de aves criadas em cada galpão. $\mathrm{O}$ abastecimento de água nos galpões era feito por meio de caixa d'água suspensa, que recebia água de outra caixa d'água instalada na superfície do solo e que era abastecida com água de poço com $170 \mathrm{~m}$ de profundidade. Até a superfície, o bombeamento era feito com conjunto motobomba submerso de $22 \mathrm{~kW}(30 \mathrm{cv}) \mathrm{com}$ vazão de 60.000 L por hora. Da caixa de superfície até o topo da caixa elevada, o bombeamento era feito com conjunto motobomba instalado na caixa de superfície com $11 \mathrm{~kW}(15 \mathrm{cv})$ de potência e vazão de 100.000 L por hora. Da caixa d'água suspensa em diante, a água era distribuída por gravidade para todos os galpões da granja. A energia associada à água de bebida foi estimada com o consumo de energia elétrica direta (motobombas de 22 e $11 \mathrm{~kW}$ ) para que a água atinja o galpão das aves. Para a água consumida nos nebulizadores, além da energia gasta pelos conjuntos motobomba de abastecimento da caixa d'água central da granja, adicionou-se a energia gasta pelo conjunto motobomba dos nebulizadores, o qual possuía $3,7 \mathrm{~kW}(5 \mathrm{cv})$ de potência e atendia a seis galpões. $\mathrm{O}$ consumo de gás liquefeito de petróleo (GLP) foi determinado por meio de pesagens dos botijões, antes da entrada do lote e após o período de aquecimento das aves, obtendo-se a massa (kg) do gás consumido nesse período. Para a determinação do consumo de energia elétrica, foi instalado no galpão um medidor de energia elétrica marca GE Inepar. O consumo médio de energia foi obtido de forma direta, ou seja, realizando-se quatro leituras semanais diretamente no medidor e anotando-se o horário da leitura, o que permitiu o cálculo do consumo médio diário (kWh). Os equipamentos elétricos utilizados no galpão para cada lote, durante o período estudado e suas respectivas potências, são apresentados na Tabela 1 . 
TABELA 1. Equipamentos elétricos utilizados no galpão e suas respectivas potências.

\begin{tabular}{|c|c|c|}
\hline Equipamentos & Quantidade & Potência \\
\hline Silo para armazenagem de ração & 1 & 1 motor $1,47 \mathrm{~kW}(2 \mathrm{cv})$ \\
\hline Sistema de alimentação para a distribuição da ração & 1 & 1 motor $1,47 \mathrm{~kW}(2 \mathrm{cv})$ \\
\hline Lâmpadas & 17 & $60 \mathrm{~W}$ \\
\hline Comedouros tipo calha & 2 linhas & 1 motor $1,47 \mathrm{~kW}(2 \mathrm{cv})$ \\
\hline Sistema de nebulização & 22 bicos & 1 motor $3,7 \mathrm{~kW}(5 \mathrm{cv}) / 3$ galpões \\
\hline Ventiladores & 16 & 1 motor $0,4 \mathrm{~kW} \mathrm{(1/2} \mathrm{cv)/un}$ \\
\hline Bomba de alta pressão & 1 & $1.200 \mathrm{~W}$ \\
\hline
\end{tabular}

- Mão-de-obra, máquinas e implementos, instalações e equipamentos: As estimativas de tempo de utilização de mão-de-obra, máquinas e implementos, instalações e equipamentos para a realização dos manejos de rotina no galpão foram realizadas anotando-se o tempo (horas) necessário de cada item para realização de cada tarefa. $\mathrm{O}$ dia de trabalho adotado na granja, para efeito de todos os cálculos, foi considerado de 7,33 horas. Nas Tabelas 2 e 3, são apresentados as máquinas e os implementos, e instalações e equipamentos utilizados no galpão comercial de frangos de corte durante o período estudado.

TABELA 2. Máquinas e implementos utilizados em cada lote no sistema de produção de frangos de corte: consumo de combustível e tempo de utilização.

\begin{tabular}{lccccc}
\hline Máquina $^{1}$ & $\begin{array}{c}\text { Peso } \\
(\mathrm{kg})\end{array}$ & $\begin{array}{c}\text { Quantidade } \\
\text { (unidade) }\end{array}$ & $\begin{array}{c}\text { Consumo } \\
(\mathrm{L})\end{array}$ & $\begin{array}{c}\text { Tempo de Utilização } \\
\text { (horas) }\end{array}$ & $\begin{array}{c}\text { Vida Útil } \\
\text { (horas) }\end{array}$ \\
\hline Trator MF 235 & 2.200 & 1 & 7,520 & 2,874 & 10.000 \\
Bobcat frota 17 & 1.850 & 1 & 4,548 & 1,402 & 10.000 \\
Bobcat frota 18 & 1.860 & 1 & 2,150 & 1,232 & 10.000 \\
Caminhão 1113 & 6.620 & 1 & 6,339 & 3,510 & 10.000 \\
Trator Valmet 68 & 3.030 & 1 & 3,667 & 0,350 & 10.000 \\
Pá carregadora Case W20 & 10.190 & 1 & 6,632 & 0,981 & 10.000 \\
Implemento & & & & & 0,350 \\
Enxada rotativa & 130 & 1 & 0,016 & 1,304 & 10.000 \\
Pulverizador KO p/2.000 L & 620 & 1 & 0,060 & & \\
'D́leo diesel + lubrificante + graxa & & & & &
\end{tabular}

TABELA 3. Instalações e equipamentos utilizados em cada lote no sistema de produção de frangos de corte.

\begin{tabular}{ll}
\hline Especificação & Quantidade \\
\hline Galpão & $1.176 \mathrm{~m}^{2}$ \\
Lança-chamas a gás & 1 unidade \\
Bomba alta pressão & 1 unidade \\
Cortina & $499,20 \mathrm{~m}^{2}$ \\
Comedouros tipo calha & 2 linhas \\
Bebedouros tipo pendular & 50 unidades \\
Ventiladores & 16 unidades \\
Sistema de nebulização & 22 bicos (tubulação de PVC - 25 mm) \\
Silo para armazenagem de ração & 1 unidade \\
Sistema de alimentação para a distribuição da ração & 1 unidade \\
Aquecedores a gás & 24 unidades \\
\hline
\end{tabular}


Caracterização dos componentes energéticos direta e indiretamente envolvidos no sistema de produção de frangos de corte

$\mathrm{Na}$ caracterização dos componentes energéticos, foram consideradas as seguintes mensurações para cada lote estudado:

Energia direta:

- número e pesos médios (kg) das aves vivas, descartes e mortas: pinto de um dia; por fase e ao abate;

- combustível: óleo diesel, óleo lubrificante e graxa (L);

- ração (kg), água (L), eletricidade (kWh) e GLP (kg): consumo por ave e por fase;

- maravalha e cama de frango: quantificação total e por ave $(\mathrm{kg})$;

- mão-de-obra: horas.

Energia indireta:

- máquinas e equipamentos: consumo, horas;

- instalações e equipamentos: utilização, $\mathrm{m}^{2}$, horas.

\section{Determinação do valor energético dos componentes direta e indiretamente envolvidos no sistema de produção de frangos de corte}

Para cada lote, foram coletados dados dos componentes energéticos de interesse, direta e indiretamente envolvidos no sistema de produção de frangos de corte, e posteriormente transformados em unidades calóricas. A unidade referencial utilizada na formação das planilhas de fluxo energético foi o kcal. Para facilitar a visualização dos resultados obtidos, nos resultados finais (Tabelas 7 e 8 ), utilizou-se da unidade Mcal.

Para as determinações de energia total da ração e cama de frango, foram coletadas amostras das mesmas, sendo realizadas análises em amostras de ração para cada fase (pré-inicial, inicial, engorda e final). As amostras foram secas em estufa com circulação forçada de ar $\left(50-54{ }^{\circ} \mathrm{C}\right)$ até o peso constante e, após, moídas em moinho de facas Marconi MA 048.

Para as determinações de energia total nas aves, utilizou-se da metodologia descrita em SILVA (1995). Foram selecionados 20 pintos de um dia (peso médio 0,046 kg) e seis aves adultas (sendo três fêmeas e três machos com 47 dias e peso médio 2,200 kg), as quais foram abatidas, sendo as carcaças congeladas, posteriormente cortadas em pedaços, usando-se serra elétrica H. Benecke e moídas em Picador de Carne marca C.A.F. 114 DS, por três vezes consecutivas, para a obtenção de amostras homogêneas. Foram, então, levadas à estufa com circulação forçada de ar $\left(50-54{ }^{\circ} \mathrm{C}\right)$ até peso constante (72 horas). Posteriormente, as amostras foram moídas em moinho de bolas Marconi MA 350 , em função do alto teor de gordura.

Uma vez preparadas as amostras de ração, material base para a cama, cama de frango e aves, determinou-se o teor de energia bruta, utilizando-se de bomba calorimétrica Parr 1281.

As estimativas das quantidades de energia referentes à mão-de-obra, máquinas e implementos, combustível, óleo lubrificante para motor e graxa, e instalações e equipamentos foram realizadas utilizando-se dos coeficientes energéticos descritos na Tabela 4 e, no caso de instalações, equipamentos máquinas e implementos, considerou-se a depreciação energética de cada item. 
TABELA 4. Alguns componentes das entradas energéticas em galpão de frangos de corte e seus respectivos coeficientes energéticos.

\begin{tabular}{|c|c|c|}
\hline Componente de Entrada & Coeficiente Energético & Vida Útil (anos) \\
\hline 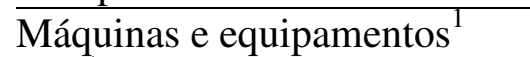 & $20.000 \mathrm{kcal} \mathrm{kg}^{-1}$ & 10 \\
\hline Aço ${ }^{1}$ & $15.000 \mathrm{kcal} \mathrm{kg}^{-1}$ & 20 \\
\hline $\mathrm{PVC}^{1}$ & $28.667 \mathrm{kcal} \mathrm{kg}^{-1}$ & 40 \\
\hline Energia elétrica $^{1}$ & $859 \mathrm{kcal} \mathrm{kWh}^{-1}$ & \\
\hline Instalações de madeira $^{2}$ & $14.074 \mathrm{kcal} \mathrm{m}^{-2}$ & 30 \\
\hline Óleo lubrificante $^{3}$ & $9.205 \mathrm{kcal} \mathrm{litro}^{-1}$ & \\
\hline $\mathrm{Graxa}^{3}$ & $10.320 \mathrm{kcal} \mathrm{kg}^{-1}$ & \\
\hline Trabalho humano ${ }^{4}$ & $900 \mathrm{kcal}$ por homem por $8 \mathrm{~h}$ & \\
\hline Biogás com $65 \%$ de metano 5 & $5.339 \mathrm{kcal} \mathrm{m}^{-3}$ & \\
\hline Óleo diesel ${ }^{6}$ & $9.159 \mathrm{kcal} \mathrm{litro}^{-1}$ & \\
\hline Madeira $^{6}$ & $2.500 \mathrm{kcal} \mathrm{kg}^{-1}$ & \\
\hline $\mathrm{GLP}^{7}$ & $11.100 \mathrm{kcal} \mathrm{kg}^{-1}$ & \\
\hline Energia hidráulica $^{8 \mathrm{a}}$ & $0,59 \mathrm{kcal}$ litro $^{-1}$ & \\
\hline Energia hidráulica $^{8 b}$ & $0,85 \mathrm{kcal}$ litro $^{-1}$ & \\
\hline
\end{tabular}

\section{- Estimativa da energia contida nas aves (kcal)}

$$
\left.\mathrm{E}_{\text {aves }}, \mathrm{kcal}=\left(\mathrm{n}^{\circ} \text { de aves }\right)(\mathrm{PV}, \mathrm{kg})(\text { teor de } \mathrm{MS}, \mathrm{kg} \mathrm{kg}) \text { (coeficiente energético, } \mathrm{kcal} \mathrm{kg}^{-1} \mathrm{MS}\right)
$$

\section{- Estimativa da energia contida na ração (kcal)}

$$
\mathrm{E}_{\text {ração }}, \mathrm{kcal}=(\text { consumo de ração, } \mathrm{kg})\left(\text { teor de } \mathrm{MS}, \mathrm{kg} \mathrm{kg}^{-1}\right)\left(\text { coeficiente energético, } \mathrm{kcal} \mathrm{kg}^{-1} \mathrm{MS}\right)
$$

- Estimativa da energia contida no GLP (kcal)

$$
\mathrm{E}_{\mathrm{GLP}}, \mathrm{kcal}=(\text { peso, } \mathrm{kg})\left(\text { coeficiente energético, } \mathrm{kcal} \mathrm{kg}^{-1}\right)
$$

- Estimativa da energia contida na maravalha e cama de frango (kcal)

$$
\mathrm{E}_{\mathrm{MeCF}}, \mathrm{kcal}=(\text { peso, } \mathrm{kg})\left(\text { teor de MS, } \mathrm{kg} \mathrm{kg}^{-1}\right)\left(\text { coeficiente energético, } \mathrm{kcal} \mathrm{kg}^{-1} \mathrm{MS}\right)
$$

- Estimativa da energia elétrica (kcal)

$$
\mathrm{E}_{\text {Eletr }}, \mathrm{kcal}=(\text { consumo, } \mathrm{kWh})\left(\text { coeficiente energético, } \mathrm{kcal} \mathrm{kWh}^{-1}\right)
$$

- Estimativa da energia referente às máquinas e equipamentos (kcal)

$$
\mathrm{E}_{\text {máq ou equip }}, \mathrm{kcal}=(\mathrm{DE}, \mathrm{kg})\left(\text { coeficiente energético, } \mathrm{kcal} \mathrm{kg}^{-1}\right)
$$

A depreciação energética (DE) de máquinas e equipamentos foi calculada de acordo com BEBER (1989), assim:

$$
\mathrm{DE}(\mathrm{kg})=\frac{\text { peso }(\mathrm{kg})-10 \% \text { do peso }(\mathrm{kg})}{\text { vida útil }(\mathrm{h})} \text { tempo de utilização }(\mathrm{h})
$$

- Estimativa da energia referente às instalações (kcal)

$$
\mathrm{E}_{\text {instalações }}, \mathrm{kcal}=\left(\mathrm{DE}, \mathrm{m}^{2}\right)\left(\text { coeficiente energético, } \mathrm{kcal} \mathrm{m}^{-2}\right)
$$


A depreciação energética (DE) das instalações foi adaptada de BEBER (1989), assim:

$\mathrm{DE}(\mathrm{kg})=\frac{\text { área }\left(\mathrm{m}^{2}\right)-10 \% \text { da área }\left(\mathrm{m}^{2}\right)}{\text { vida útil }(\operatorname{anos})}$ tempo de utilização (anos)

- Estimativa da energia referente à mão-de-obra (kcal)

$\mathrm{E}_{\mathrm{MO}}, \mathrm{kcal}=($ horas trabalhadas/homem $)\left(\right.$ coeficiente energético, $\left.\mathrm{kcal}_{\text {hora }}{ }^{-1}\right)$

Cálculo do coeficiente de eficiência energética $(\xi)$

A eficiência energética foi calculada pela relação energia produzida e consumida, assim:

$$
\xi=\frac{\sum E_{\text {produção }}}{\sum E_{\text {consumo }}}
$$

em que,

$$
\begin{aligned}
& \mathrm{E}_{\text {produção }}=\text { estimativa de energia produzida no processo de produção } \sum\left(\mathrm{E}_{\text {direta produção }}+\mathrm{E}_{\text {indireta produção }}\right) \\
& \mathrm{E}_{\text {consumo }}=\text { estimativa de energia consumida no processo de produção } \sum\left(\mathrm{E}_{\text {direta consumo }}+\mathrm{E}_{\text {indireta consumo }}\right)
\end{aligned}
$$

\section{Energia passível de recuperação através da biodigestão anaeróbia da cama de frangos}

Estimou-se a energia passível de recuperação por meio da biodigestão anaeróbia da cama de frangos, utilizando-se de cálculo que considerou a produção total de cama, potencial da cama de frangos para produção de biogás e valor energético do biogás (conforme Tabela 4). Para efeito de comparação, com esses dados, foi calculada a equivalência energética do biogás em relação ao GLP, o qual é comercializado em botijões de $13 \mathrm{~kg}$ e equivalem a $30 \mathrm{~m}^{3}$ de biogás cada um.

\section{RESULTADOS E DISCUSSÃO}

$\mathrm{Na}$ Tabela 5, são apresentados os coeficientes médios energéticos, em kcal kg-1, e os teores médios de matéria seca $\left(\mathrm{kg} \mathrm{kg}^{-1}\right)$ dos componentes energéticos de entrada e saída. Na Tabela 6, apresentam-se as quantificações médias dos componentes energéticos de entrada e saída, utilizados para os cálculos do balanço energético, propriamente dito, e coeficiente de eficiência energética, cujos resultados são apresentados nas Tabelas 7 e 8.

TABELA 5. Coeficientes médios energéticos ( $\left.\mathrm{kcal} \mathrm{kg}^{-1} \mathrm{MS}\right)$ e teores médios de matéria seca (\%) dos componentes de entrada e saída, diretamente envolvidos no sistema de produção de frangos de corte.

\begin{tabular}{lcc}
\hline Componente de Entrada & $\mathrm{kcal} \mathrm{kg}^{-1} \mathrm{MS}$ & $\mathrm{MS} \mathrm{( \% )}$ \\
\hline Maravalha de pínus & $4.148,5$ & 52,29 \\
Pintos de 1 dia & $5.242,9$ & 24,97 \\
Ração pré-inicial & $3.732,2$ & 92,34 \\
Ração inicial & $3.776,0$ & 92,50 \\
Ração engorda & $4.173,2$ & 93,29 \\
Ração final & $4.082,9$ & 92,06 \\
\hline Componente de Saída & $\mathrm{kcal} \mathrm{kg}^{-1} \mathrm{MS}$ & $\mathrm{MS}(\%)$ \\
\hline Cama de frango & $3.640,5$ & 76,12 \\
Frangos & $6.169,1$ & 37,34 \\
Aves mortas & $6.232,4$ & 30,96 \\
\hline
\end{tabular}


TABELA 6. Quantificação dos componentes energéticos médios de entrada e de saída, direta e indiretamente envolvidos no sistema de produção de frangos de corte.

\begin{tabular}{lr}
\hline Componente de Entrada & \\
\hline Maravalha, kg MN & $13.443,5$ \\
Pintos de 1 dia, kg MN & 673,0 \\
Ração pré-inicial, kg MN & $2.350,0$ \\
Ração inicial, kg MN & $16.837,5$ \\
Ração engorda, kg MN & $32.900,0$ \\
Ração final, kg MN & $13.950,0$ \\
Energia elétrica, kWh & $2.647,4$ \\
GLP, kg & 548,3 \\
Água, L & $132.105,2$ \\
Mão-de-obra, horas & 267,8 \\
Máquinas e equipamentos, horas & 12,0 \\
Combustível ${ }^{1}$, L & 32,3 \\
Instalações, m ${ }^{2}$ & 5,9 \\
Equipamentos, horas & $6.445,6$ \\
\hline Componente de Saída & $27.702,5$ \\
\hline Cama de frango, kg MN & $35.586,8$ \\
Frangos, kg MN & 595,4 \\
\hline Aves mortas, kg MN & \\
\hline
\end{tabular}

'óleo diesel, óleo lubrificante e graxa

Embora sejam apresentados os dados médios de oito lotes de criação dos frangos, os fluxos líquidos de energia observados apresentaram semelhança entre os diferentes lotes, com variação mínima, a qual tem relação com o número de aves criadas, duração de cada lote e modificações nos manejos, por tratar-se de galpão comercial.

O fluxo líquido médio de energia demonstrou que a atividade possui alto consumo energético. $\mathrm{O}$ total de energia envolvida no processo foi de 749,4 $10^{3}$ Mcal por lote, em média, com 585,9 $10^{3}$ Mcal por lote correspondentes à entrada total média. Desse total de energia que entrou no sistema, $51,2 \%$ foi indireta. Do total de energia direta que foi investida no galpão, 10,2\% correspondeu à maravalha; $0,3 \%$ às aves; $86,5 \%$ à ração; $0,8 \%$ à eletricidade, e 2,1\% ao GLP. A energia referente à água, ao combustível e à atividade humana (mão-de-obra) foi irrisória neste estudo e, apesar de computadas na matriz de cálculo energético, suas participações, em porcentagem, apresentaram valores próximos a zero, perfazendo um total de $0,14 \%$, quando somados (Figura 1).

Observa-se que, em algumas situações, determinadas formas de energia podem representar pouco em termos porcentuais no balanço energético, como é o caso da energia elétrica, GLP, água, combustível e mão-de-obra neste estudo, porém ao balanço energético sugere-se que se associe um balanço econômico e ambiental, uma vez que, embora com baixo valor energético, determinado vetor pode significar impactos econômicos, ambientais e sociais importantes, como é o caso do GLP, que, embora apresente baixa contribuição na matriz energética do galpão, é energia originária de fonte não renovável, sempre relacionada com impactos ambientais e econômicos, devido à flutuação de preços e instabilidade na oferta. 
TABELA 7. Energia consumida e produzida (Mcal) no sistema de produção de frangos de corte.

\begin{tabular}{lr}
\hline Energia Consumida (entrada), Mcal & \\
\hline Maravalha & $29.104,2$ \\
Pintos de 1 dia & 895,7 \\
Ração pré-inicial & $8.096,7$ \\
Ração inicial & $58.819,1$ \\
Ração engorda & $128.059,4$ \\
Ração final & $52.448,0$ \\
Energia elétrica & $2.274,1$ \\
GLP & $6.085,8$ \\
Água & 80,5 \\
Mão-de-obra & 296,3 \\
Máquinas e equipamentos & 30,1 \\
Combustível & $10.007,7$ \\
Instalações e equipamentos & $289.861,5$ \\
\hline Energia Produzida (saída), Mcal & \\
Cama de frango & $76.494,7$ \\
Frangos & $85.789,6$ \\
Aves mortas & $1.223,0$ \\
\hline
\end{tabular}

De toda a energia envolvida no processo de produção de frangos de corte, dentro do galpão, $78,2 \%$ refere-se à energia de entrada, ao passo que a energia de saída corresponde a $21,8 \%$, resultando em um coeficiente de eficiência energética de 0,28 (28\%) - Tabela 8, ou seja, para cada 100 Mcal de energia importada pelo sistema, obtêm-se $28 \mathrm{Mcal}$ de energia produzida. Segundo QUESADA et al. (1987) e BEBER (1989), coeficiente de eficiência energética menor que "um" indica um sistema que importa, praticamente, toda a energia consumida no processo produtivo, característica de sistemas altamente tecnificados, como é o caso da produção de frangos de corte.

CARVALHO (1999), ao realizar balanço energético em granja de postura, verificou coeficientes de eficiência energética de 0,$19 ; 0,29 ; 0,58$ e 0,89, para as fases de cria, recria, pré-postura e postura, respectivamente. $\mathrm{O}$ coeficiente médio de eficiência energética obtido nesta pesquisa corrobora $\mathrm{o}$ relatado por OSTRANDER (1980), ou seja, sistemas de produção de frangos de corte possuem baixas eficiências energéticas em contraste com as apresentadas pelo sistema de produção de ovos.

Da forma como se apresentam as energias de saída, ou seja, 46,8\% referente à cama de frangos (vendida como fertilizante); 52,5\% referente aos frangos produzidos (consumo), e $0,7 \%$ referente às aves mortas e descartadas, apenas essa última não possui destinação com aproveitamento de energia, já que as mesmas são dispostas em fossos nessa granja. Uma alternativa que pode tornar aproveitável a energia de saída via aves mortas é a compostagem das carcaças, já implementada em muitas granjas avícolas em nosso País. Pode-se afirmar que praticamente toda a energia produzida (93\%) é exportada do sistema, ou seja, a energia proveniente da cama de frango, quando totalmente vendida, e a energia proveniente dos frangos produzidos.

A quantidade média de energia requerida para produzir $1 \mathrm{~kg}$ de frango vivo, no sistema estudado, foi igual a 16,5 Mcal.

Ressalta-se que este foi um estudo de caso, realizado com base em um galpão específico e que é comum encontrar sistemas semelhantes consumindo e/ou produzindo quantidades diferentes de energia. Essas diferenças podem ser devidas às variações de instalações, equipamentos e manejo, entre outros fatores. Embora os resultados deste estudo expressem um caso específico, acredita-se que esses venham colaborar não só com informações do perfil de consumo de energia pela Avicultura de Corte, mas também com estudos que venham otimizar a porção da energia retornável ao sistema. 
TABELA 8. Balanço energético do sistema de produção de frangos de corte.

\begin{tabular}{lc}
\hline Componente & Média \\
\hline Total de entrada, $10^{3} \mathrm{Mcal}$ & 585,9 \\
Total de saída, $10^{3} \mathrm{Mcal}$ & 163,5 \\
Eficiência energética & 0,28 \\
Fluxo líquido de energia, $10^{3} \mathrm{Mcal}$ & 422,4 \\
Energia para produzir $1 \mathrm{~kg}$ de frango vivo, Mcal & 16,5 \\
\hline
\end{tabular}

Quanto às possibilidades de incorporação de maior quantidade de energia no sistema, deve-se considerar a reciclagem do total de cama produzida, em biogás.

Levando-se em consideração o potencial médio de produção de biogás obtido por SANTOS (2001) (biodigestão anaeróbia da cama de frango com 50 dias de retenção hidráulica) igual a $0,1001 \mathrm{~m}^{3} \mathrm{~kg}^{-1}$ de cama in natura, e a produção média de cama no período igual a $27.702,5 \mathrm{~kg}$, observa-se que poderiam ser recuperados $2.773,02 \mathrm{~m}^{3}$ de biogás, o equivalente a 14.805,2 Mcal ou 101 botijões com $13 \mathrm{~kg}$ de GLP, gerando economia, já que se deixa de adquirir GLP para o consumo no galpão.

Embora no balanço energético a proporção de energia provinda do GLP seja relativamente baixa, em termos econômicos, essa mesma energia toma proporções maiores, já que é uma energia direta e derivada do petróleo, que tem seu preço constantemente sofrendo altas, sendo esse custo computado nos custos anuais da empresa.

A produção de biogás apresenta-se como uma possibilidade de agregar valor ao resíduo gerado, podendo ser utilizado dentro do galpão em equipamentos adaptados, favorecendo um equilíbrio energético, uma vez que a cama de frango in natura é exportada do galpão, resultando em maior desequilíbrio. O biogás pode ainda, parcial ou totalmente, ser redirecionado para outros galpões ou setores.

Há de se considerar, também, o benefício adicional do biofertilizante, que apresenta em sua composição nutrientes prontamente disponíveis para as plantas.

Além da independência energética que a empresa terá com o uso do biogás, seu uso permitirá um balanço energético, econômico e ambiental equilibrado, esse último, em especial, de difícil valoração, porém com contribuição significativa para o atendimento das bases de desenvolvimento sustentável.

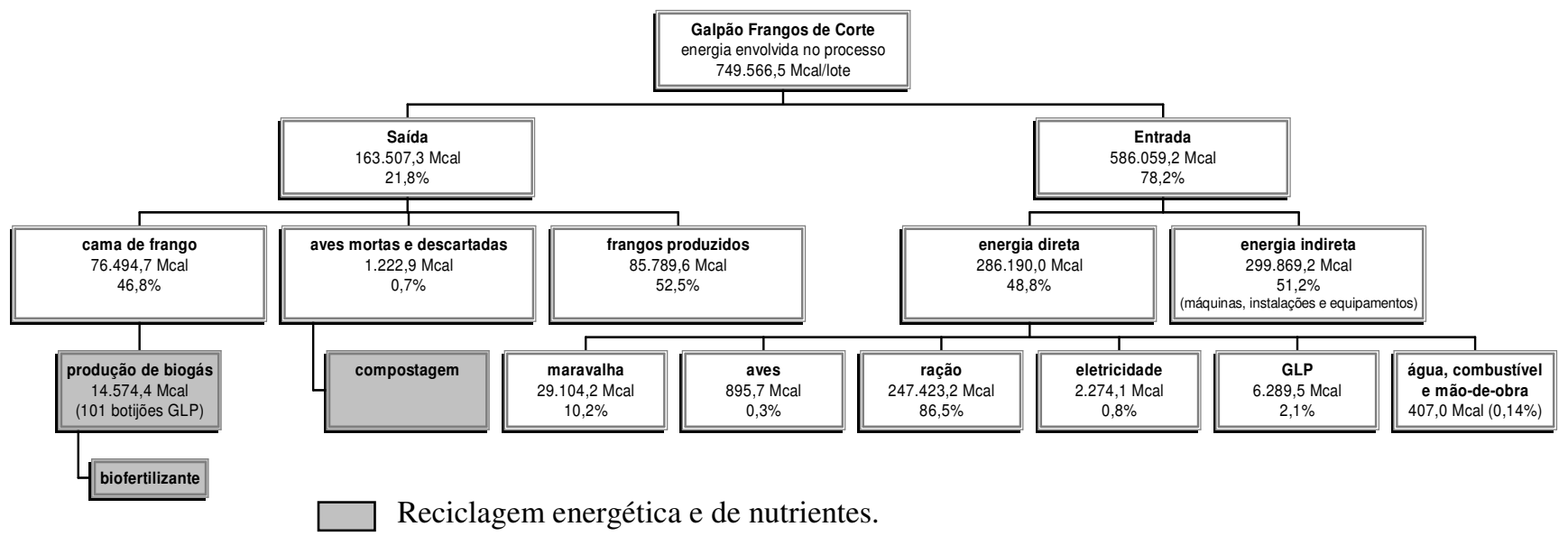

FIGURA 1. Balanço energético total apresentado no sistema de produção de frangos de corte, com possibilidades de agregação de valor dos resíduos gerados. 


\section{CONCLUSÕES}

A quantidade média de energia requerida para produzir $1 \mathrm{~kg}$ de frango vivo, no sistema estudado, foi igual a 16,48 Mcal.

De toda a energia envolvida no processo de produção de frangos de corte, dentro do galpão, $78,2 \%$ diz respeito à energia que entra no sistema, ao passo que a energia de saída corresponde a $21,8 \%$, resultando em um coeficiente de eficiência energética de 0,28 (28\%).

O uso do processo de biodigestão anaeróbia da cama pode retornar ao sistema de produção $46,7 \%$ da quantidade de energia que sai, possibilitando a diminuição dos custos com aquecimento das aves, já que o biogás produzido poderá substituir o GLP, além dos benefícios adicionais creditados à economia ambiental.

São necessários estudos adicionais para incrementar os dados disponíveis na literatura sobre energia na agropecuária, particularmente em galpões de frangos de corte, pois são raras as pesquisas que tratam do balanço energético, como um todo, nesse setor.

\section{AGRADECIMENTOS}

Os autores agradecem à Fundação de Amparo à Pesquisa do Estado de São Paulo - FAPESP.

\section{REFERÊNCIAS BIBLIOGRÁFICAS}

BEBER, J.A.C. Eficiência energética e processos de produção em pequenas propriedades rurais. 1989. 295 f. Dissertação (Mestrado em Extensão Rural) - Universidade Federal de Santa Maria, Santa Maria, 1989.

BRASIL. Ministério de Minas e Energia. Balanço energético nacional. Brasília, 2003. Disponível em: <http://www.mme.gov.br/paginasInternas.asp?url=../BEN/default.asp> Acesso em: 1ํㅡㅁ 2004.

CAMPANHOLA, C.; LUIZ, A.J.B.; LUCCHIARI JR., A. O problema ambiental no Brasil: agricultura. In: ROMEIRO, A.R.; REYDON, B.P.; LEONARDI, M.L.A. (Org). Economia do meio ambiente: teoria, políticas e a gestão de espaços regionais. Campinas: UNICAMP/IE, 1996. cap.3, p.251-81.

CAMPOS, A.T. de; FERREIRA, W.A.; YAMAGUCHI, L.C.T.; RESENDE, H.; ALMEIDA, F.M. Balanço econômico e energético na produção de silagem de milho em sistema intensivo de produção de leite. Engenharia Rural, Piracicaba, v.9, n.1, p.10-20, 1998.

CARVALHO, S.M.R. Balanço energético e potencial de produção de biogás em granja de postura comercial na região de Marília - SP. 1999. 87 f. Tese (Doutorado em Energia na Agricultura) - Faculdade de Ciências Agronômicas, Universidade Estadual Paulista, Botucatu, 1999.

GABRIEL, L.R.A.; TEIXEIRA, N.M.; ARAGON, F.F.; SERAPHIM, O.J. Estimativa do cálculo da energia direta embutida no processo de refinação do óleo de amendoim. In: CONGRESSO BRASILEIRO DE ENGENHARIA AGRÍCOLA, 22., 1993, Ilhéus. Anais... Ilhéus: Sociedade Brasileira de Engenharia Agrícola, 1993a. p. 723-6.

GABRIEL, L.R.A.; SERAPHIM, O.J.; ARAGON, F.F.; TEIXEIRA, N.M. Estimativa do cálculo da energia indireta embutida no processo de refinação do óleo de amendoim. In: CONGRESSO BRASILEIRO DE ENGENHARIA AGRÍCOLA, 22., 1993, Ilhéus. Anais... Ilhéus: Sociedade Brasileira de Engenharia Agrícola, 1999b, p.738-49.

OSTRANDER, C.E. Energy use in agriculture poultry. In: PIMENTEL, D. (Ed.) Handbook of energy utilization in agriculture. Boca Raton: CRC Press, 1980. p. 379-92. 
PIMENTEL, D. Handbook of energy utilization in agriculture. Boca Raton: CRC Press, 1980. 475 p.

QUESADA, G.M.; BEBER, J.A.C.; SOUZA, S.P. Balanços energéticos agropecuários: uma proposta metodológica para o Rio Grande do Sul. Ciência e Cultura, Campinas, v.39, n.1, p.20-8, 1987.

ROSS, C.C.; DRAKE, T.J.; WALSH, J.L. Handbook of biogas utilization. 2. ed. Atlanta: U.S. Department of Energy, 1996. pág. irreg.

SANTOS, T.M.B. Balanço energético e adequação do uso de biodigestores em galpões de frangos de corte. 2001. 167 f. Tese (Doutorado em Produção Animal) - Faculdade de Ciências Agrárias e Veterinárias, Universidade Estadual Paulista, Jaboticabal, 2001.

SILVA, R. Exigências de energia metabolizável para frangas de postura de 1 a 18 semanas de idade. 1995. 76 f. Dissertação (Mestrado em Produção Animal) - Faculdade de Ciências Agrárias e Veterinárias, Universidade Estadual Paulista, Jaboticabal, 1995.

STOUT, B.A. Handbook of energy for world agriculture. New York: Elsevier Science, 1990. 504 p.

ULBANERE, R.C. Análise dos balanços energético e econômico relativa à produção e perdas de grãos de milho no Estado de São Paulo. 1988. 127 f. Tese (Doutorado em Energia na Agricultura) Faculdade de Ciências Agronômicas, Universidade Estadual Paulista, Botucatu, 1988. 